\title{
ESTUDO DE FRATURA E FALHAS SUPERFICIAIS EM ARAMES TREFILADOS BTC *
}

Tiago Salzmann Vilela ${ }^{1}$

\section{Resumo}

Durante a produção de arames pelo processo de trefilação diversas falhas superficiais e internas podem ocorrer. Esses defeitos podem ocasionar fratura do arame no processo dos clientes. Um dos defeitos mais clássicos na trefila, denominado "pé de corvo" ou "Chevron", foi estudado neste trabalho. As principais causas desse defeito estão ligadas à falhas no processo de lubrificação, podendo ser relacionados ao tipo e quantidade de sabão usados durante a trefilação, como também a ocorrência de defeitos no fio máquina empregado e ou, "caminho do arame". Para esse estudo, diversos defeitos superficiais em fio máquina foram selecionados e então posteriormente trefilados observando a ocorrência do problema nos arames produzidos. Os defeitos superficiais no fio máquina foram coletados de bobinas segregadas no estoque e foram soldados e identificados, a fim de facilitar posterior localização do defeito. A partir do estudo foi possível identificar as causas da ocorrência das falhas por defeito de pé de corvo e propor medidas preventivas que mitigassem o problema.

Palavras-chave: Defeitos superficiais; Arame BTC trefilado; Falha de pé de corvo; Chevron.

\section{STUDY OF FRACTURE AND FAILURE SURFACE IN LCS DRAWN WIRE}

\begin{abstract}
During the production of wire by drawing process, several external and internal faults may occur. These defects can cause wire fracture in the process of customers. One of the most classic defects in wire drawing, called "Crow Foot" or "Chevron", was studied in this work. The main causes of this defect are linked to failure in the lubrication process and may be related to the type and amount of lubricants used during drawing, as well as the occurrence of defects in the wire rod and, or "path of the wire". For this study, several surface defects in wire rod were selected and then subsequently drawn observing the occurrence of the problem in wire. The surface defects were collected from the segregated stock wire rod and were welded and identified in order to facilitate subsequent location of the defect. Through this study, it was possible to identify the causes of the faults by "crow foot" defects and propose preventive measures that would mitigate the problem.
\end{abstract}

Keywords: Surface defects; LCS drawn wire; Failure Crow Foot; Chevron.

1 Engenheiro de Materiais, Assessor Técnico/Facilitador de Melhorias, Tecnologia de Processos, Gerdau Aços Brasil - Gerdau Cotia, SP, Brasil. 


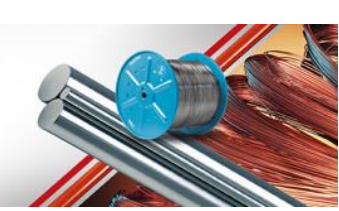

\section{INTRODUÇÃO}

De acordo com Cetlin e Helman [1] o processo de trefilação de arames é extremamente antigo, datado de cerca de 3000 antes de Cristo e usado principalmente para produção de fios de ouro e prata para joalheria. Até cerca de 1800 depois de Cristo a trefilação ocorria de forma manual (o esforço era feito pelo homem, animais ou rodas de água) usando-se uma placa de ferro com diversos furos cônicos de diâmetros decrescentes. Na figura 1 pode ser visto o modelo antigo usado e um desenho de um trefilador em torno de 1450 depois de Cristo.

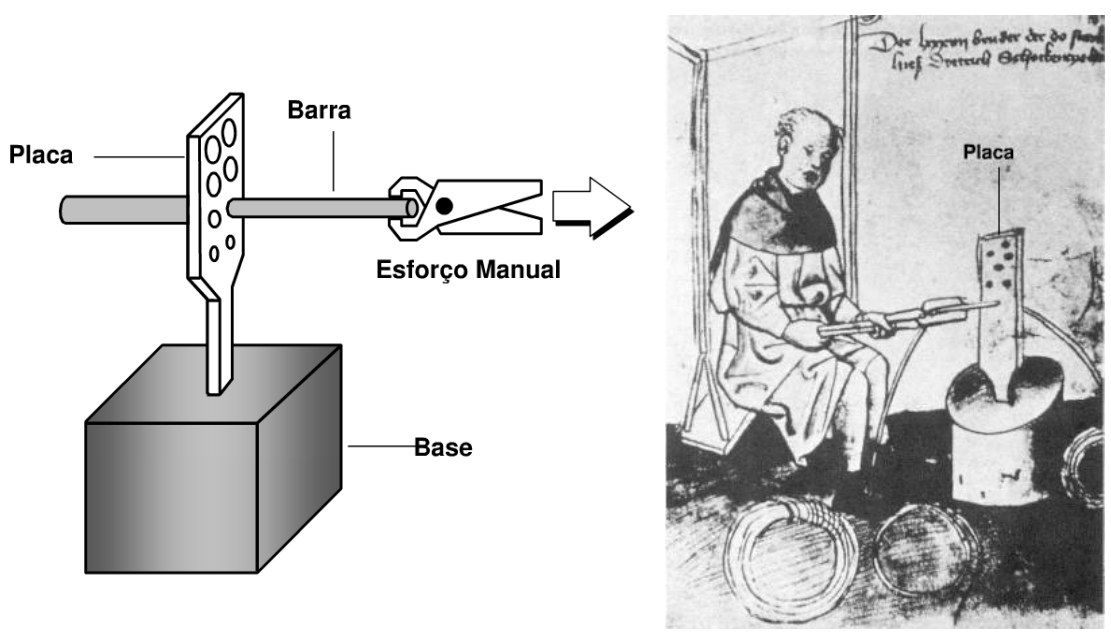

Figura 1. Ferramentas usadas para trefilação e desenho antigo de trefilador [1].

De maneira geral, hoje os arames são produzidos através da passagem do fio por uma ferramenta denominada fieira e tracionado por blocos consecutivos. O processo pode ter um ou múltiplos passes de trefilação, chegando a diâmetros de arame muito finos. Na figura 2 pode ser visto um esquema de trefilação com os blocos e as fieiras.

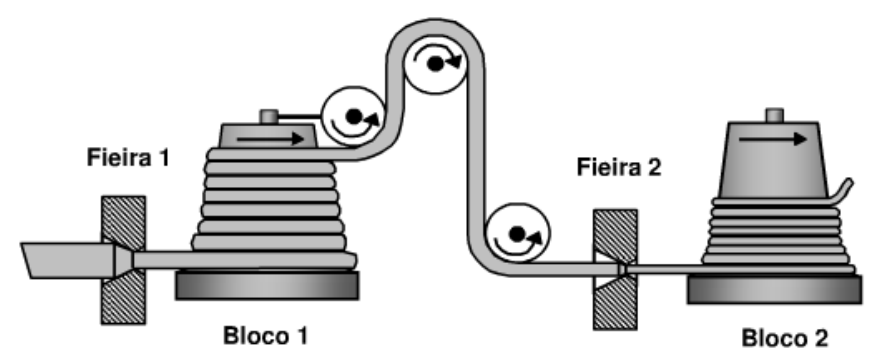

Figura 2. Sistema de trefilação de arames com uso de blocos e fieiras [1].

De maneira geral, antes de iniciar a trefilação do material, o fio máquina necessita ser decapado. A decapagem do fio máquina pode ser feita através de ataque químico em banho (solução de ácido clorídrico) ou através de limpeza mecânica através de dobramento alternado, escovas rotativas metálicas, jateamento com granalha, prensa de palha de aço ou lixas abrasivas, seguido ou não de tratamento superficial com banho salino. O objetivo dessa etapa é retirar por completo a carepa oriunda do processo de laminação do fio máquina e facilitar o processo de trefilação. 
Após o processo de decapagem, o material inicia propriamente dito o processo de trefilação. De acordo com Cetlin [2], para auxiliar esse processo são utilizados lubrificantes sólidos com a finalidade de reduzir o atrito do aço com a fieira.

Na figura 3 pode ser visto o esquema de lubrificação do arame durante processo de trefilação.

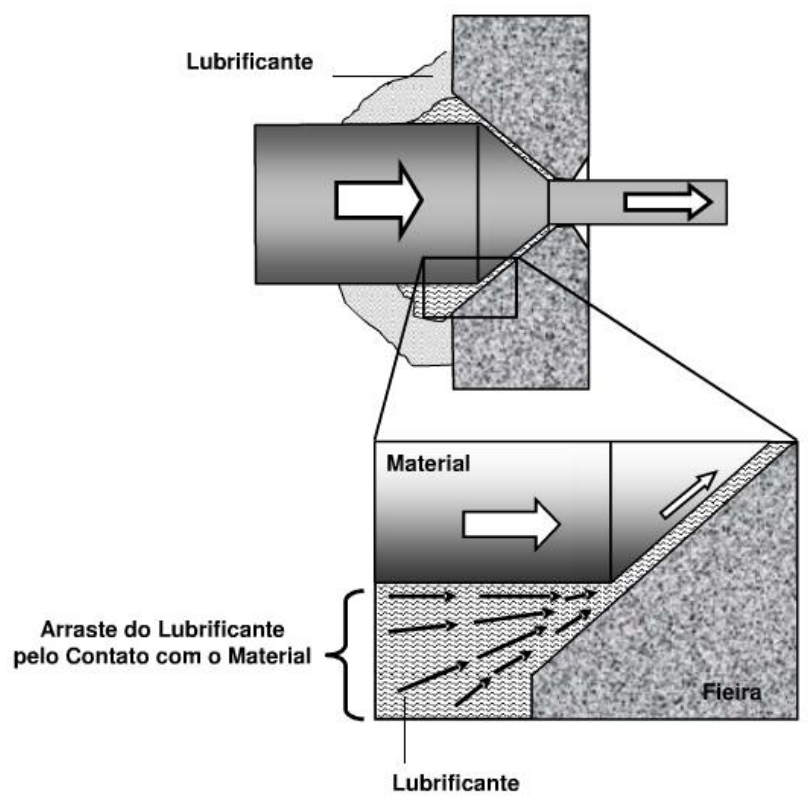

Figura 3. Esquema de lubrificação do arame durante trefilação [2].

De acordo com Button [3], durante a trefilação, podem ocorrer algumas falhas que geram defeitos no produto e podem levar à quebra do material durante o processo na fábrica ou no cliente. Os principais defeitos de trefilação são relacionados abaixo:

- Quebras por tração (fratura em taça-cone);

- Quebras internas (ponta de lápis);

- Quebras na solda;

- Quebras iniciadas na superfície do material (pé de corvo ou Chevron).

A grande maioria das quebras na trefilação ocorre a partir da superfície do material. Elas começam quando por alguma razão abre-se uma pequena fratura na superfície do material durante a trefilação. Quando há essa pequena fratura, o lubrificante entra nela no momento que o material passa pela fieira, levantando um pouco a parte de trás da fratura, forçando o material para trás. De acordo com Cetlin [2] o resultado desse processo é que a fratura na superfície aumenta e fica mais profunda. Na figura 4 pode ser visto o fenômeno descrito acima. 


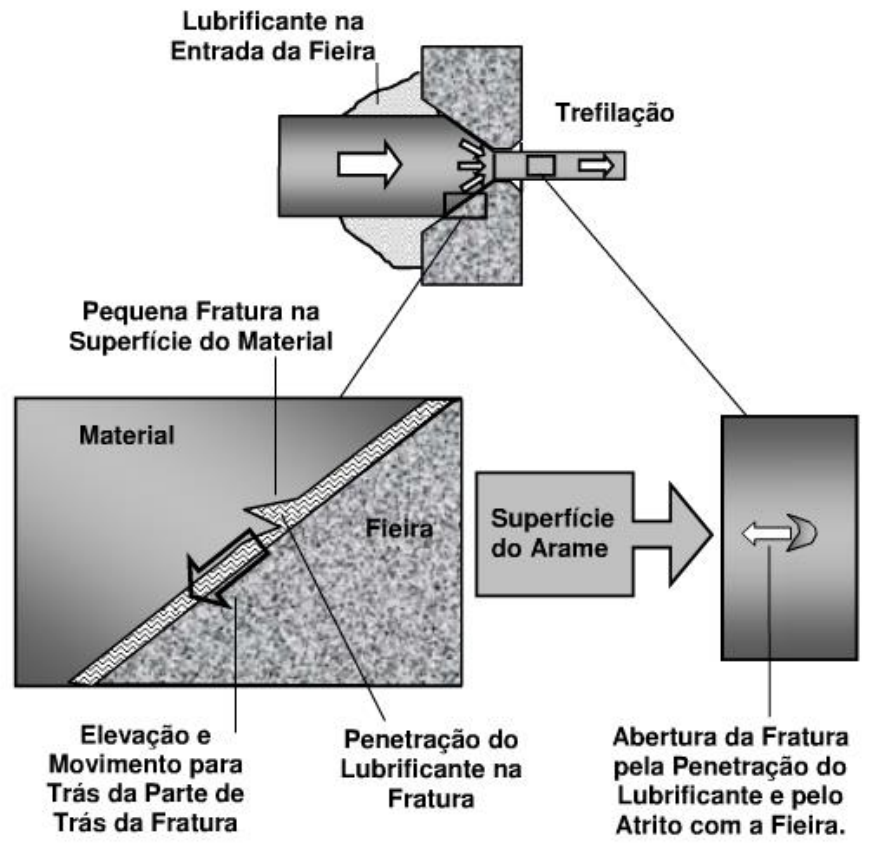

Figura 4. Formação das falhas superficiais durante trefilação [2].

Depois de alguns passes (entre 4 e 7 passes) a fratura superficial já está bem grande e o arame arrebenta ou na frente da fieira ou em alguma polia. Avaliando a característica visual do defeito formado é possível observar a semelhança do defeito com as pegadas que os corvos deixam no chão. Daí o nome de pé de corvo [2]. $\mathrm{Na}$ figura 5 pode ser visto o esquema do defeito denominado pé de corvo.
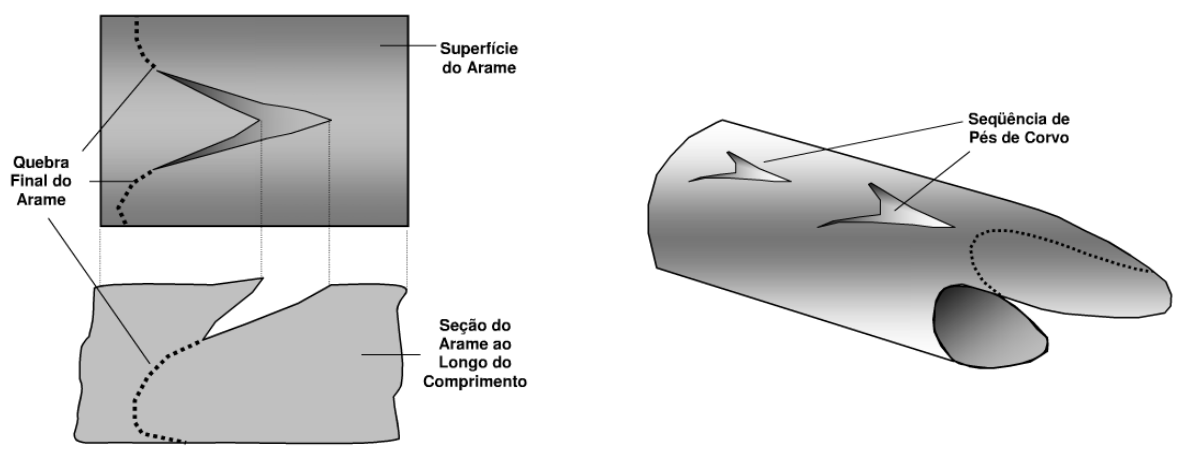

Figura 5. Formação das falhas superficiais de pé de corvo durante trefilação [2].

De acordo com Cetlin [2] existem diversas causas para a ocorrência das fraturas iniciais na superfície. As principais são listadas abaixo:

- Defeitos na superfície do fio máquina causados pela laminação;

- Falhas de lubrificação durante trefilação;

- Defeitos causados pela manipulação/transporte do fio máquina até a máquina;

- Defeitos causados pelo contato do arame com partes móveis da máquina. 


\section{MATERIAIS E MÉTODOS}

\subsection{Estudo de Caso: Ocorrência de Fratura por Pé de Corvo em Arame BTC}

Para avaliar e estudar a causa das quebras em arames Baixo teor de carbono que ocorriam no processo de trefilação foram separadas diversas amostras de quebras e as mesmas foram analisadas. Foi realizado um brainstorming com operadores, equipe de manutenção e áreas de apoio técnico para identificar cada uma das causas.

Após realização do levantamento de causas, foram coletadas amostras de defeitos em fio máquina em bobinas segregadas no estoque. Vale ressaltar que essas bobinas estavam destinadas para sucatamento por causa de defeitos superficiais causadas no transporte.

Os defeitos foram separados, identificados e quantificados quanto à severidade. Para separar e facilitar a identificação dos defeitos foi soldado entre cada defeito um arame cobreado de forma que, após a trefilação, os defeitos pudessem ser localizados e avaliados.

Finalmente, foram escolhidas algumas amostras e fez-se uma análise da evolução do defeito através de cada passe, observando a alteração da forma do defeito.

\section{RESULTADOS E DISCUSSÃO}

\subsection{Ocorrência de Fratura por Pé de Corvo ou Chevron em Arame BTC}

Através de brainstorming e revisão da literatura foi possível identificar as prováveis causas para a ocorrência das quebras. Abaixo pode ser visto os principais problemas elencados no brainstorming:

Aspectos de lubrificação:

- Tipo incorreto de sabão utilizado;

- Sabão queimado (perdeu suas características de lubrificação); Aspectos de fieira e redução:

- Jogo de fieiras (ângulo) inadequado;

- Plano de passes incorreto (sobrecarregando algum ponto específico); Aspectos de dano no fio máquina:

- Dano no fio máquina no estoque e transporte até unidade;

- Dano no fio máquina durante movimentação interna;

- Dano no fio máquina por embaraçamento durante desbobinamento; Aspectos de dano no arame:

- Dano durante caminho no arame (roletes travados e ou partes móveis);

Em seguida passou-se a verificar cada um dos pontos relacionados no brainstorming. Nos aspectos de lubrificação, fieiras, plano de passes e danos no arame (caminho do arame) não foram encontradas anormalidades, estando esses pontos todos em conformidade com o processo e com as orientações dos fabricantes (sabão, fieira e equipamento).

Foi então realizada uma inspeção criteriosa no estoque e foi constatado que havia bobinas com dano de manuseio. Essas bobinas foram imediatamente segregadas. Das bobinas segregadas, foram selecionados 16 amostras de defeitos e esses defeitos foram fotografados, identificados e quantificados por nível de severidade. Vale ressaltar que o nível de severidade foi atribuído de maneira qualitativa, observando a extensão do dano, a profundidade do mesmo e se haviam rebarbas. 
5올 Seminário de Trefilação

Arames, Barras e Tubos de Metais

Ferrosos e Năo Ferrosos

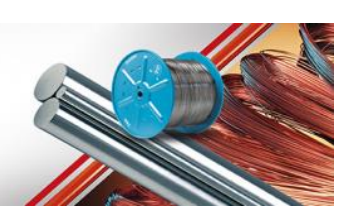

Para solda das amostras, um fio de aço cobreado com dimensão e teor de carbono igual ao do fio máquina original foi utilizado. É importante ressaltar que para o procedimento de solda foram tomados os devidos cuidados para que a própria solda não gerasse um defeito em si no material.

$\mathrm{Na}$ figura 6 pode ser visto um painel com seis amostras coletadas contendo defeitos em fio máquina. Essas amostras foram caracterizadas como defeitos de nível severo. Elas receberam numeração de 1 a 6 conforme figura abaixo.

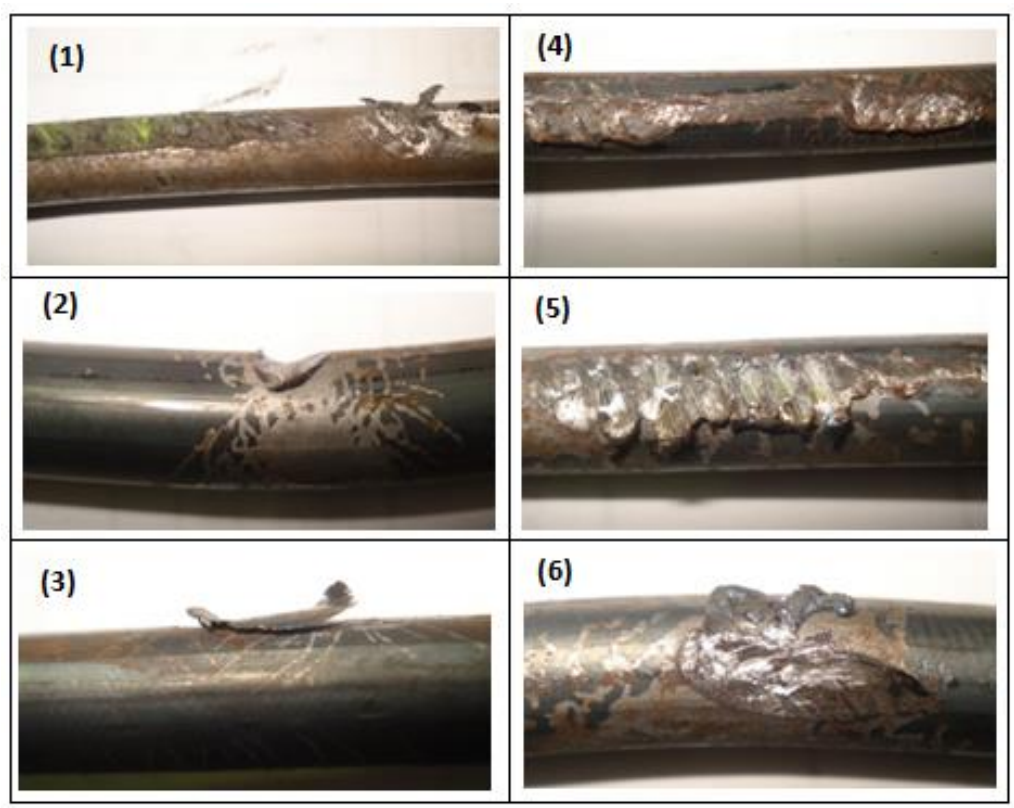

Figura 6. Defeitos encontrados no fio máquina caracterizados como nível severo (2x de aumento).

Na figura 7 pode ser visto o segundo painel de defeitos de fio máquina contendo mais seis amostras. Essas amostras foram caracterizadas como defeitos de nível moderado e foram numeradas de 7 a 12 .

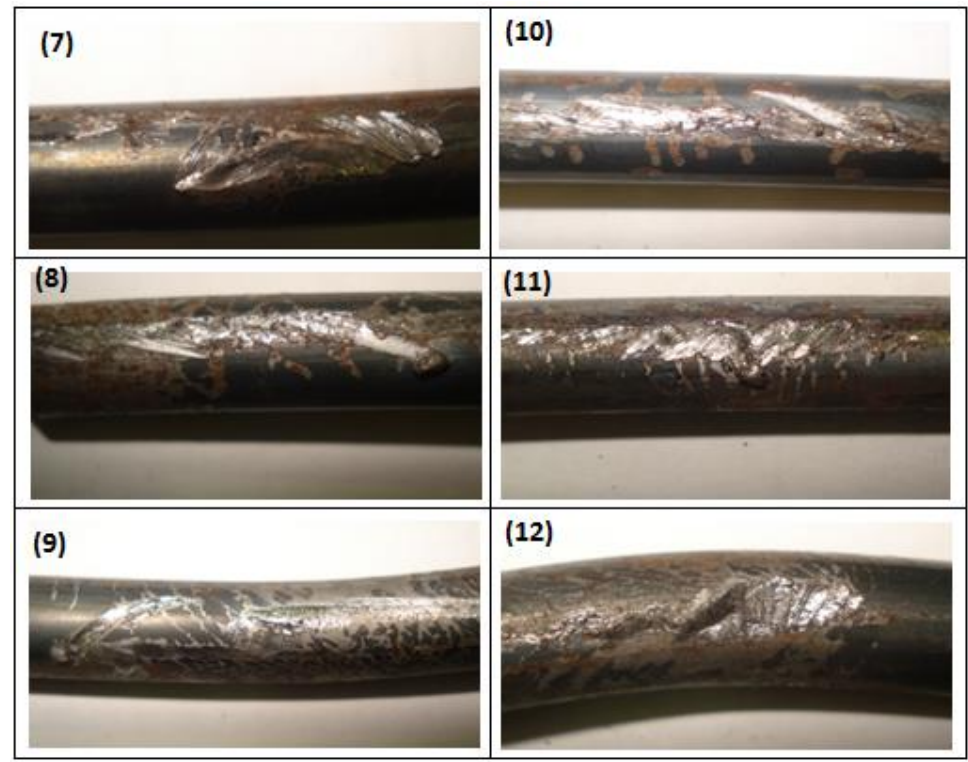

Figura 7. Defeitos encontrados no fio máquina caracterizados como nível moderado (2x de aumento). 
5ำ Seminário de Trefilação

Arames, Barras e Tubos de Metais Ferrosos e Não Ferrosos

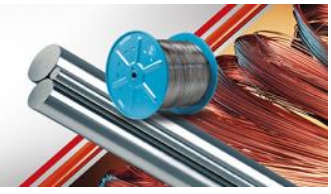

Finalmente na figura 8 pode ser visto o último painel de defeitos de fio máquina contendo mais quatro amostras. Essas amostras foram caracterizadas como defeitos de nível leve e foram numeradas de 13 a 16.
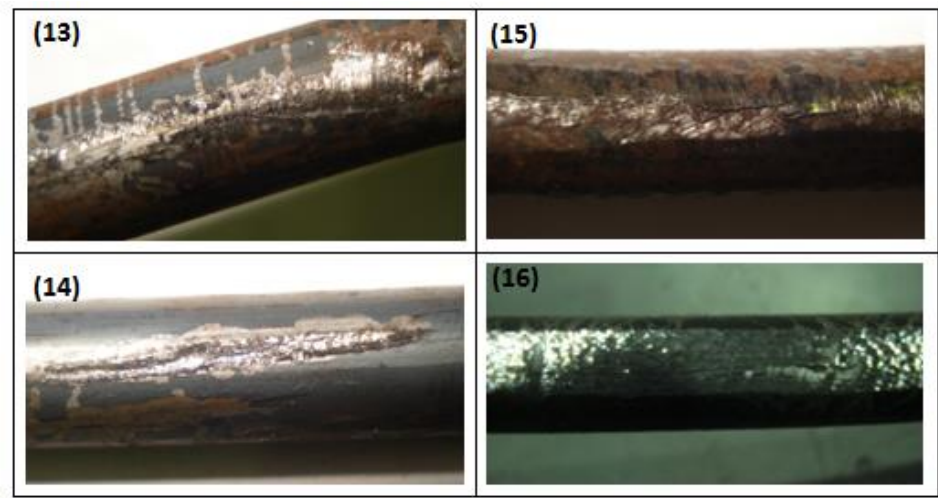

Figura 8. Defeitos encontrados no fio máquina caracterizados como nível leve (2x de aumento).

A velocidade de trefilação foi mantida conforme padrão, bem como os demais parâmetros tais como lubrificantes, jogo de redução e etc. A análise dos defeitos foi realizada utilizando-se um estereoscópio de baixa ampliação (até 10x). Não foi necessário realizar nenhum tipo de preparação nas amostras. Para captura das imagens foi utilizado uma máquina fotográfica digital convencional. Os resultados obtidos se encontram na figura 9. É possível observar que em todas as amostras do grupo caracterizado como severo e moderado houve aparecimento de defeitos de pé de corvo. As amostras número 5 e 6 chamam atenção por gerarem defeitos mais profundos, inclusive com quebra durante processo de trefilação.

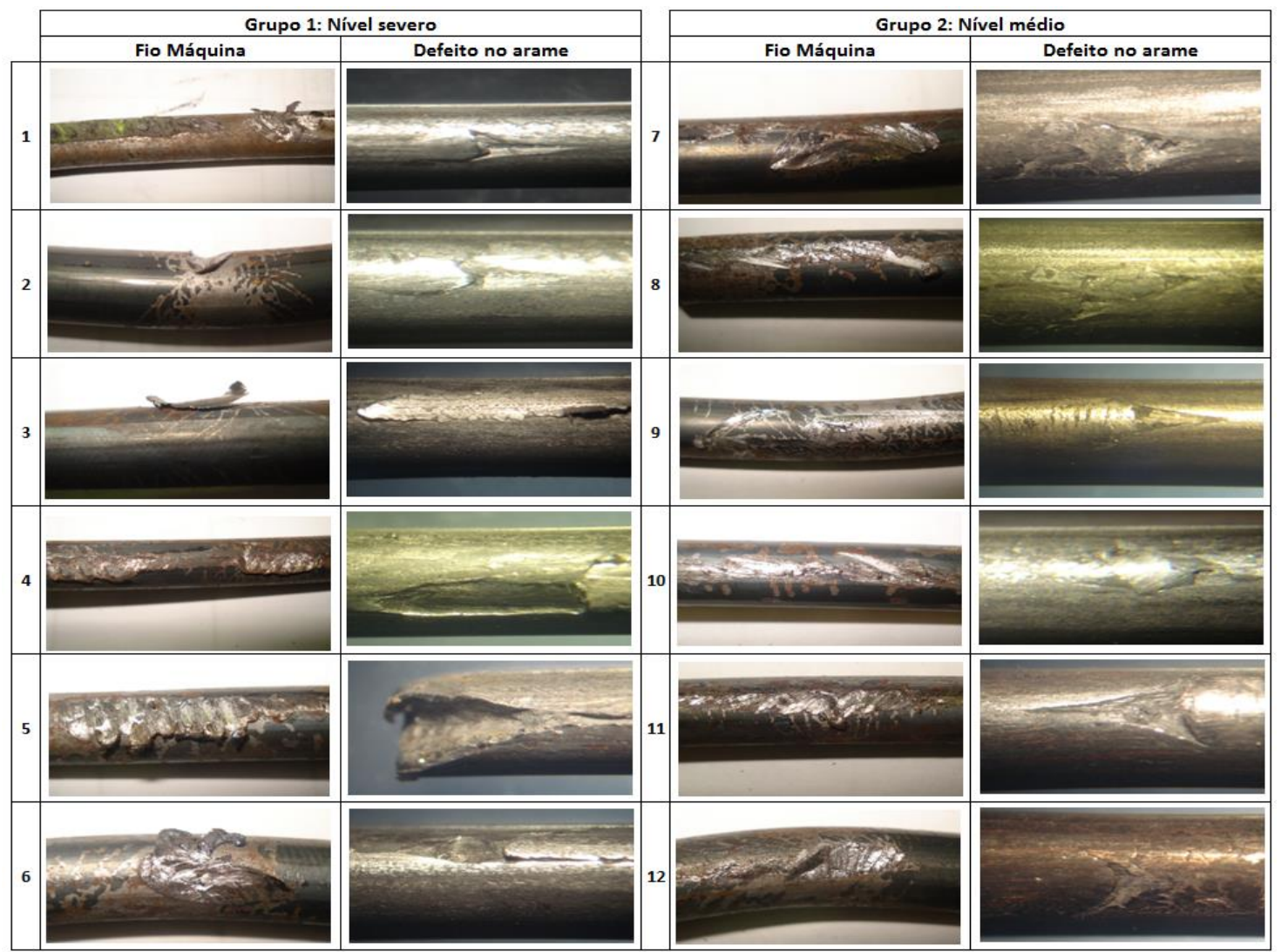

Figura 9. Comparativo entre defeitos no fio máquina e arame após trefilação ( 7 x de aumento).

\footnotetext{
* Contribuição técnica ao $5^{\circ}$ Seminário de Trefilação: Arames, Barras e Tubos de Metais Ferrosos e Não Ferrosos, 24 e 25 de novembro de 2014, São Paulo, SP, Brasil.
} 


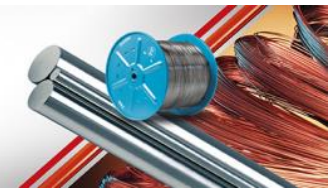

Para o grupo de amostras caracterizado como leve, houve aparecimento de pequenos defeitos de pé de corvo apenas nas amostras 15 e 16. Nas outras amostras não foi observado o defeito. Vale ressaltar que o tamanho dos defeitos gerados nas amostras do grupo de nível leve foi muito inferior aos outros grupos e necessitou-se de maior atenção inclusive para localização dos defeitos. Na figura 10 pode ser visto os defeitos encontrados no último grupo.

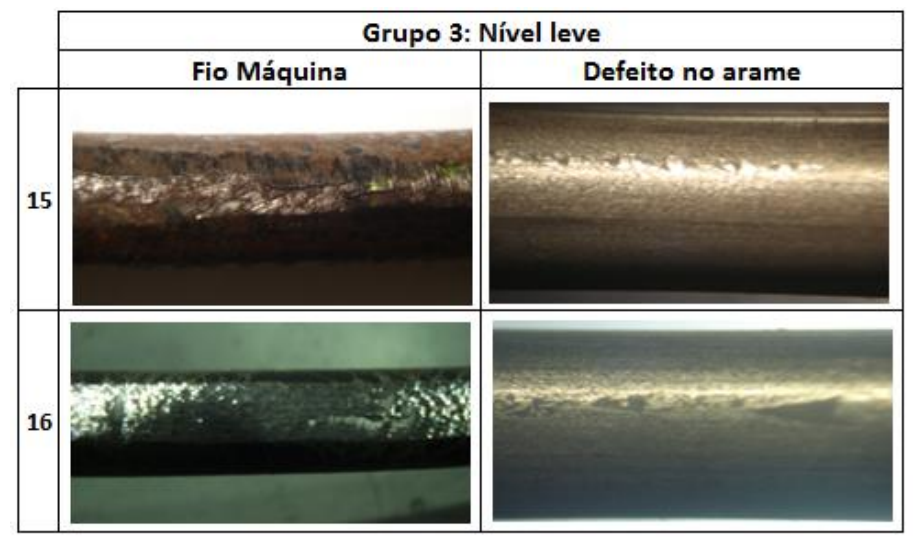

Figura 10. Comparativo entre defeitos no fio máquina e arame após trefilação ( 7 x de aumento).

Durante a observação também foi constatado defeitos na região da solda. Esses defeitos também foram avaliados e mostram que caso a região da solda não seja completamente limpa de rebarbas e defeitos essa região também pode gerar falhas de pé de corvo. Na figura 11 podem ser vistos os defeitos encontrados em algumas amostras na região da solda.

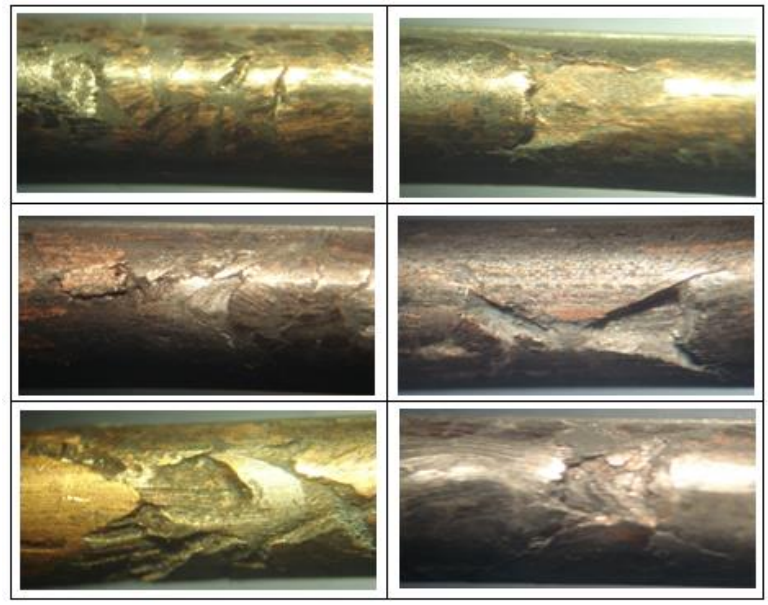

Figura 11. Defeitos observados na região da solda ( 7 x de aumento).

\subsection{Medidas Preventivas Adotadas para Eliminar as Quebras por Pé de Corvo.}

Após ser constatado que o problema de quebra na trefila ocorria em virtude do dano de manuseio no fio máquina, as medidas abaixo foram adotadas:

- Criação de padrão para movimentação dos estoques internos no fornecedor (uso de empilhadeiras, pontes e etc);

- Padronização do modal de transporte e carregamento no fornecedor; 
- Adoção de check list de recebimento de fio máquina (pela equipe de logística, como também antes do uso pelos operadores);

- Manuseio interno das bobinas com empilhadeira dotada de aríete revestido de Poliuretano;

- Estocagem das bobinas em berços de madeira;

- Criação de encartes de bolso (guia de bolso) para divulgação e sensibilização da operação;

Das ações mencionadas acima, seguem nas figuras 12, 13, 14 e 15 alguns exemplos das medidas adotadas, que após a implantação, reduziram drasticamente a ocorrência de quebras durante a trefilação ou processamento no cliente:

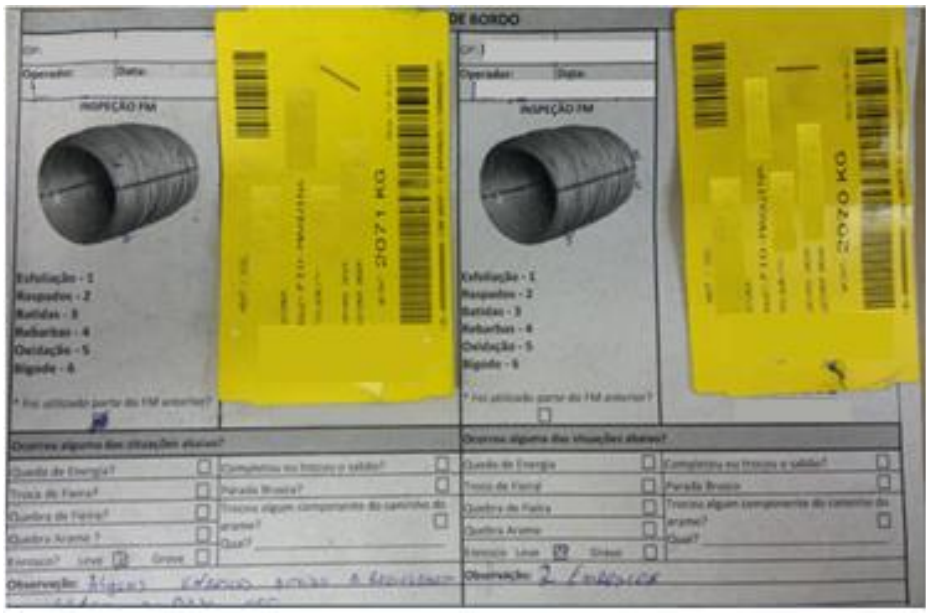

Figura 12. Check list de recebimento de fio máquina.

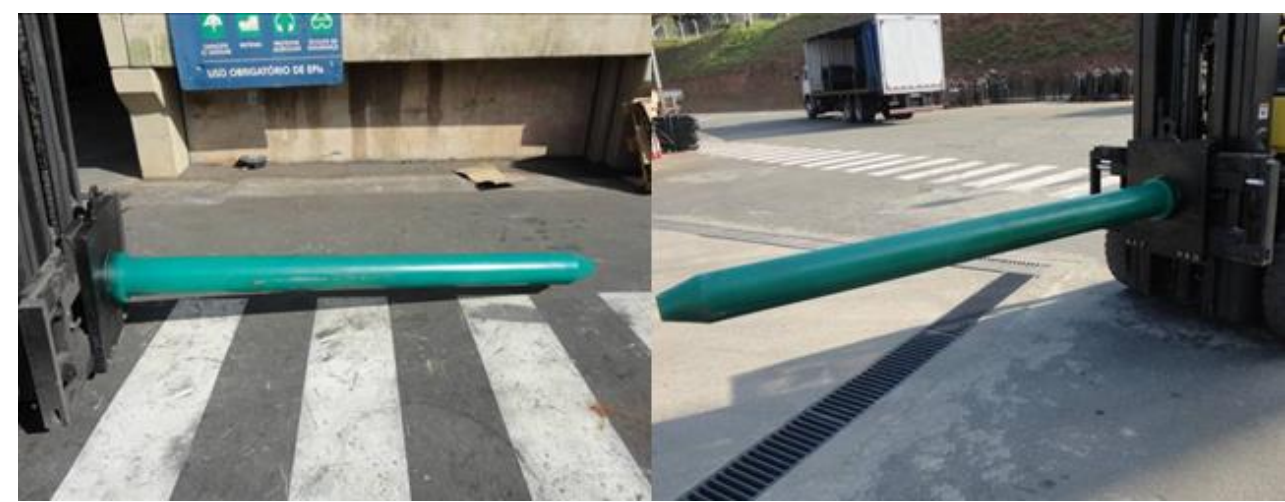

Figura 13. Empilhadeiras dotadas de aríete com Poliuretano.

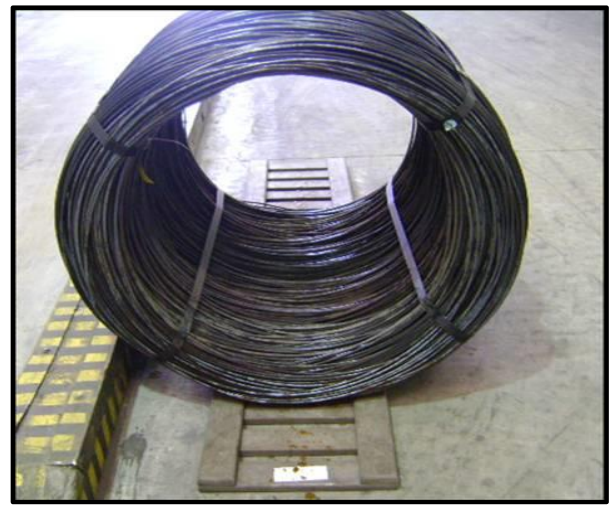

Figura 14. Berço de madeira utilizado para apoio do fio máquina. 


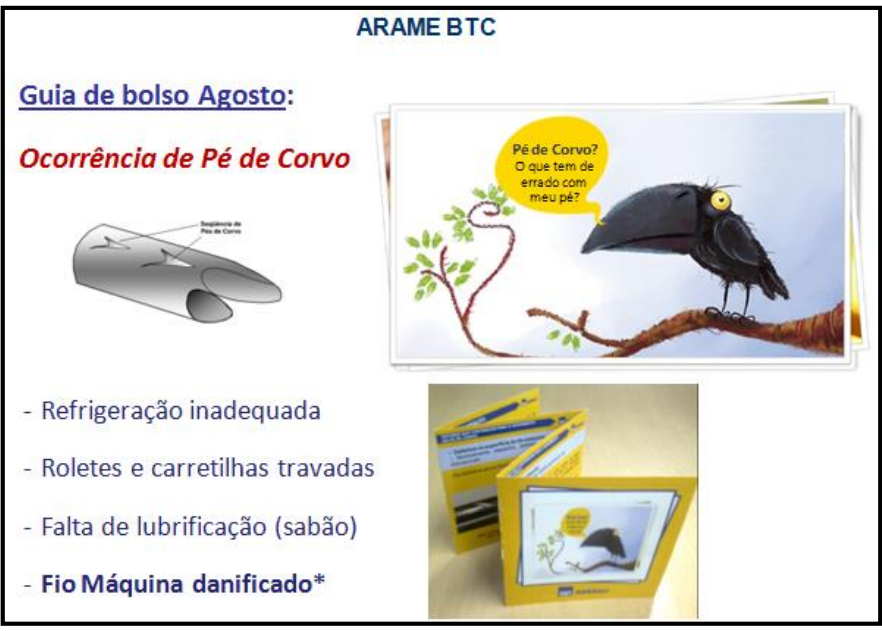

Figura 15. Guia de bolso (encarte orientativo para operação).

\section{CONCLUSÃO}

A partir desse trabalho foi possível verificar que as quebras que ocorriam no processo de trefilação eram oriundas de defeitos pré-existentes no fio máquina ou causados pela movimentação interna da logística. Os defeitos observados no fio máquina geravam após a trefilação falhas similares às encontradas no arame produzido, sendo coerente então a relação entre causa e efeito do problema.

Através de ações simples de padronização, foi possível mitigar em $90 \%$ os casos de quebras. As ações foram focadas em revisão de padrões de manuseio de fio máquina tanto no fornecedor como na unidade, contemplando baias específicas de estoque, berços de madeira, movimentação usando empilhadeiras com aríetes revestidos de Poliuretano e treinamento operacional.

\section{Agradecimentos}

Gostaria de agradecer aos consultores da Gerdau Jorge Adam Cleto Cohn e Marcos Alberto Moschen Pinto pela valorosa e imprescindível contribuição técnica no desenvolvimento deste trabalho. Agradeço também aos meus colegas de trabalho Luciana de Carvalho Affonso, Marcelo Girotto de Mattos e Tiago Nisio Gonçalves que contribuíram na revisão e execução deste trabalho.

\section{REFERÊNCIAS}

1 Cetlin PR, Helman H. Fundamentos da conformação mecânica dos metais, Guanabara Dois, São Paulo, 1983.

2 Cetlin PR. Apostila sobre Tecnologia de Trefilação de Arames de Aço, Departamento de Engenharia Metalúrgica e de Materiais da UFMG, Belo Horizonte, 1982.

3 Button ST. Apostila de Trefilação - Programa de educação continuada da ABM, Belo Horizonte, 2008. 